UCRL-ID-120392

\title{
Localized Weld Metal Corrosion in Stainless Steel Water Tanks
}

\author{
M. J. Strum
}

May 25, 1995

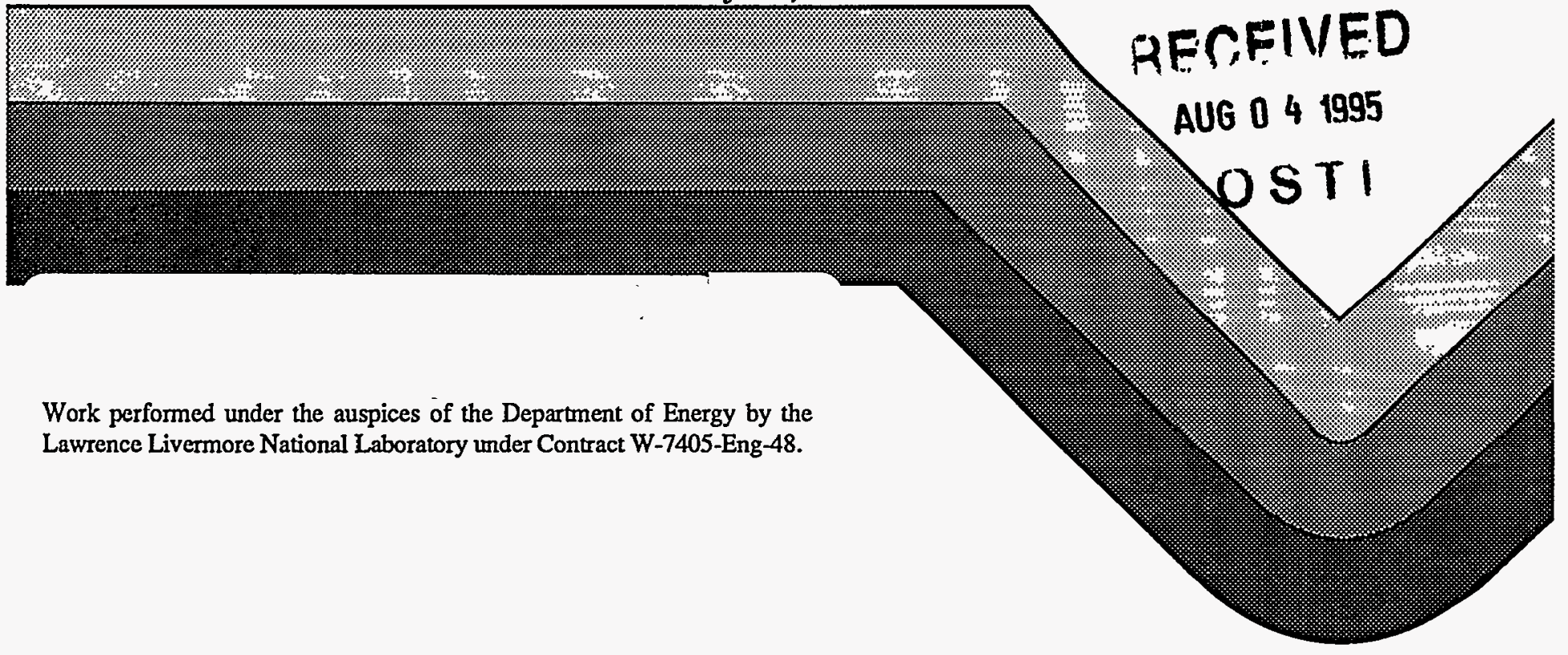




\section{DISCLAIMER}

This report was prepared as an account of work sponsored by an agency of the United States Government. Neither the United States Government nor any agency thereof, nor any of their employees, make any warranty, express or implied, or assumes any legal liability or responsibility for the accuracy, completeness, or usefulness of any information, apparatus, product, or process disclosed, or represents that its use would not infringe privately owned rights. Reference herein to any specific commercial product, process, or service by trade name, trademark, manufacturer, or otherwise does not necessarily constitute or imply its endorsement, recommendation, or favoring by the United States Government or any agency thereof. The views and opinions of authors expressed herein do not necessarily state or reflect those of the United States Government or any agency thereof. 


\section{DISCLAIMER}

\section{Portions of this document may be illegible}

in electronic image products. Images are produced from the best available original document. 
LOCALIZED WELD METAL CORROSION IN STAINLESS STEEL WATER TANKS

\author{
M. J. Strum
}

Chemistry \& Materials Science Department

Lawrence Livermore National Laboratory

May 25, 1995

DISTAUSTION OF THIS DOCURENT IS UNLIMITED

tuar 
Stainless steel (304L) air stripper tanks installed at the LLNL groundwater treatment facilities TFC and TFD developed water leaks within an unexpectedly short period of service. Corrosion testing of duplicate welds place within the TFD tanks has shown that oxidation at the underside of these welds results in rapid initiation of corrosion damage. The relatively thick oxides produced by high temperature exposure to air during welding have been determined by others [1] to be Cr-rich, leaving the surface underneath the oxide depleted in $\mathrm{Cr}$ and highly susceptible to corrosion $[1,2]$. Inspection of welds duplicating those of the TFD tank revealed oxides on the underside of the weld that were sufficiently thick to produce cracking and spallation at the oxide/metal interface, exposing the underlying surface to the aqueous environment.

Metallographic evaluation of a weld leak site removed from the TFC tank established that localized pitting and/or crevice corrosion within the resolidified weld metal is responsible for the water leaks. The corrosive attack is highly localized, initiating at the weld fusion boundary and propagating through the resolidified weld metal. The size and shape of the corroded volume, the stability of the leak rate, which remains slow, and the isolated leak locations all support a mechanism of localized corrosion vs. environmentally-assisted cracking or preexisting weld flaws. The slow leak rates and periodic self-healing of leaks observed in the tanks further suggest that an aggressive environment developed within the corrosion pits and was responsible for acceleration of the corrosion rates. The completion of corrosive penetration results in a rapid dilution of the original liquid trapped within the corrosion pit (due to replenishment of leaked water with bulk water) and a corresponding arrest of the corrosive damage. This scenario is consistent with the small diameter of the leak as observed on the outer weld surface relative to the larger subsurface size of the pit.

A number of factors were identified within the TFC and TFD tanks which increase their susceptibility to corrosive damage. These include: 1) surface oxidation on the tank interior due to welding, 2) crevices created by incomplete weld penetration on the tank interior, 3) chloride concentrations as high as $250 \mathrm{ppm}$ in the groundwater, 4) precipitation of calcium carbonate sediments. Qualification testing of alternate weld procedures showed that corrosion damage can be prevented in $304 \mathrm{~L}$ stainless steel GTA welds by welding from both sides and through prevention of oxidation through the use of an inert backing gas such as argon. Corrosion resistance was also satisfactory in GMA welds in which oxidized surfaces were postweld cleaned by wire brushing and chemically passivated in nitric acid. Further improvements in corrosion resistance are expected from a Mo-containing grade of stainless steel such as type $316 \mathrm{~L}$, although test results were similar for type $304 \mathrm{~L}$ sheet welded with type $308 \mathrm{~L}$ filler metal and type $316 \mathrm{~L}$ sheet welded with type $316 \mathrm{~L}$ filler metal. 


\section{INTRODUCTION}

Air stripper tanks installed at the LLNL groundwater treatment facilities TFC and TFD reduce the levels of volatile compounds within treated groundwater by turbulent aeration within large stainless steel tanks. Water leaks developed in the TFD tanks within approximately 2 months of service, followed by leakage in TFC tanks after a somewhat longer period. These tanks were fabricated from type 304L stainless steel sheet, $0.115^{\mathrm{m}}(2.9 \mathrm{~mm})$ in thickness. The bottom and four sides of the tanks were welded together from the outside using a gas tungsten arc (GTA) process with type $308 \mathrm{~L}$ filler metal. The two tanks installed at TFD and four duplicate tanks, welded by LLNL personnel, were overlapped along their edges by approximately $50 \%$ and manually welded in a single pass. Shielding of the welds from the atmosphere was provided by flowing argon gas through the weld nozzle but no shielding was provided on the tank interior, resulting in significant oxidation of the interior surfaces near the weld joint. The tank at TFC was fabricated in a similar manner but with a larger volume of added filler metal to produce a convex weld bead. Both weld procedures produced partial penetration welds, leaving an unwelded gap on the interior seams of the tanks.

The water leakage in these tanks occurred at numerous locations with similar characteristics: leaks all emanated from the weld metal at the bottom seams; water droplet formation was slow and isolated to point sources at each location; corrosion of the outer tank was not visible; rust colorations were carried by the water droplets. Looking inside the TFD tanks, the bottom seams were coated with rust colored deposits, which were locally very heavy, as can be seen in Figure 1. Rust colorations were present on many of the internal tack welds connecting baffles and interior partitions although some of the intermittent welds, fabricated from inside the tank, were noticeably free of corrosion products. With the exception of a few isolated discolorations on the tank floor, all of the corrosion was localized to the welded areas.

The rapid development of these water leaks far exceed the rates of general corrosion in stainless steels, pointing to an alternate source of damage. It is known that stainless steels are susceptible to many alternate forms of cracking or corrosive attack including: 1) hot cracking during weld solidification, 2) weld sensitization, in which carbide precipitation creates a weld heat affected zone (HAZ) which is susceptible to accelerated corrosion, 3) localized attack by crevice or pitting corrosion, 4) stress corrosion cracking, and 5) corrosion-assisted fatigue. In order to evaluate these mechanisms, duplicate welds were fabricated and inspected before and after exposure to the TFD environment. A leaky weld site from the TFC tank was later physically removed and metallographically prepared to directly view the internal leakage path.

The corrosion rates in stainless steels can be influenced by a number of factors. The superior corrosion resistance of stainless steels is the result of the formation of a passive Cr-oxide layer at the exposed surface. This requires a steel which contains a minimum $\mathrm{Cr}$ concentration of approximately $13 \mathrm{wt} . \%$ and conditions which allow formation of the passive oxide at exposed surfaces. Certain contaminants in the water, especially chlorides, can break down the passive oxide and allow corrosion to proceed at rates similar to that of carbon steel. In the 
presence of crevices or corrosion pits, the chlorides can create a local environment (reduced $\mathrm{pH}$ ) where corrosion proceeds unusually rapidly. In the presence of static stresses above a threshold value, chlorides can also cause rapid crack growth (stress corrosion cracking), although normally only at elevated temperatures. Additionally, fatigue loading can act synergistically with surface corrosion to cause rapid crack advance. The rate of corrosion is therefore sensitive to the local $\mathrm{Cr}$ concentration in the steel, to water chemistry (especially chloride content), to crevices or other surface characteristics that can isolate the local environment and allow acidification, to local stresses, temperature, and the amplitude of alternating loads.

To qualify modified welding procedures, corrosion testing was employed which provided evidence of specific benefits from elimination of interior crevices (associated with the partial penetration welds made from outside the tanks) and from either preventing oxidation of interior surfaces or postweld cleaning and chemically passivating the oxidized surfaces. Alternatively, the corrosion resistance is expected to be improved through the use of pitting resistant compositions such as $316 \mathrm{~L}$, by avoiding precipitate of calcium carbonate, and by maintaining low chloride concentrations.

The experimental test procedures and results are summarized in more detail within the next sections. Variables of surface oxidation, steel composition (e.g. $304 \mathrm{~L}$ vs. 316L sheet), postweld surface cleaning and chemical passivation, and cathodic protection were examined. Implications with respect to the corrosive mechanism responsible for the observed behavior and means for corrosion control are discussed with reference to the literature.

\section{RESULTS \& DISCUSSION}

\section{Duplicate GTA Welds}

Duplicate welds were fabricated using the same lot of $304 \mathrm{~L}$ material, $308 \mathrm{~L}$ filler rod, and the same welder as in construction of the six TFD-type tanks. Weld edges were overlapped approximately $50 \%$ and GTA welds produced using three different techniques, designed to span the range of potential weld chemistries in the fabrication of the existing tanks and in a repair weld. These procedures were: 1) autogenous GTA welds with no filler metal addition, 2) GTA welds with 3/32" diameter $308 \mathrm{~L}$ filler metal, and 3) autogenous GTA root pass and a $308 \mathrm{~L}$ filler pass. Argon gas shielding was applied through the weld nozzle from the outside only. Three sets of weld coupons were cut from each weld. One set was left as-welded, one set was bent around a 0.5 inch diameter mandrel to approximately $30^{\circ}$ from closure in order to visibly open any solidification cracks, and one set was cleaned by wire brushing and /or sanding to remove all visible oxidation.

Visual inspection of the as-welded and deformed welds at magnifications of up to $20 X$ gave no indications of solidification cracking in any of the welds.

Metallography of as-welded samples, shown in Figure 2, confirmed the absence of weld cracking or microfissuring in the resolidified weld metal and HAZ's (heat- 
affected zones). Etching the welds in oxalic acid confirmed the absence of HAZ sensitization which can cause accelerated corrosive atiack but is not expected in low-carbon (L-grade) materials with single-pass welds. No evidence of carbide precipitation was observed in any of the welds. All of the duplicate corner welds, shown in Figure 1, are partial penetration welds. The effective welded section increased from $52 \%$ of the uniform plate thickness for procedure \#1, to $64 \%$ for procedure \#2, and $98 \%$ for procedure \#3.

Short term corrosion testing of these welds confirmed the preferential corrosion of surfaces oxidized during welding. In these tests, weld samples were compared when left as-welded and when surface cleaned using a sanding paddle and/or wire brushing. Inspection of the corrosion samples after 1 day of air stripping operations and 4 days total water exposure showed corrosion products localized to the oxidized regions and no signs of rusting in areas protected by argon shielding gas or areas cleaned after welding. The root of the welds could not be mechanically cleaned due to the incomplete weld penetration. This incomplete penetration leaves a crack-like defect at the root (underside) of the weld which is difficult to access. Therefore, bead-on-plate welds, produced on the test coupons were used to evaluate the effectiveness of postweld surface cleaning. The heavily oxidized backside of these welds showed heavy rusting while the postweld cleaned portions were free from discoloration.

While these tests indicate the cause of surface rusting and a means to limit or prevent it from occurring, corrosive penetrations by this mechanism alone are expected to be minor. Anticipated corrosion rates due to general corrosion in the tank environment are insufficient to explain the rapid failures. A synergism is expected, however, between surface oxidation which initiates corrosion and the creation of localized pitting and crevice corrosion environments that cause rapid corrosive penetrations.

For comparison of base metal composition effects, welds were also produced from $316 \mathrm{~L}$ sheet using procedures 1 and 2 , e.g. either autogenous GTA welds (procedure \#1) or welds with matching $316 \mathrm{~L}$ filler metal (procedure \#2). Both the $304 \mathrm{~L}$ and $316 \mathrm{~L}$ welds were immersed into the TFD tank as a single batch. Like the $304 \mathrm{~L}$ welds, no rusting occurred at the top surfaces of the $316 \mathrm{~L}$ welds, which were $\rightarrow$ shield with argon gas. The underside of the $316 \mathrm{~L}$ welds showed minor rusting at a few localized positions, with the undersides of the 304L welds showing more uniform discolorations characteristic of the interference colorations from thin oxide films. Of related interest, minor rust discolorations were also noted at crevices created by the stainless steel wire supporting the test coupons at wire twists and at punched holes in the weld coupons. These results suggest that the water tank conditions were conducive to crevice corrosion. 


\section{Analysis of Leak Lecation in TFC Tank}

Subsequent to the testing of duplicate welds, the value of inspecting an actual leak site to view the corrosive path and morphology became obvious. A leak site in TFC was located and removed from the tanks with saw cuts (the tank was immediately repaired by GTA welding an equal sized patch in its place). The weld was visually inspected and photographed from both sides, as shown in Figure 3. The weld underbead (with the weld root appearing as a crack-like discontinuity in Fig. 3a) was fully covered with rust and contained thick corrosion deposits adjacent to the leak location. The top of the weld was relatively clean with no obvious rusting and the leak site is barely visible in Fig. $3 \mathrm{~b}$ as a defect approximately $0.5 \mathrm{~mm}$ in diameter positioned at the fusion boundary. The weld was cut near the expected leak site and both sides polished and etched. Three different locations were examined, as shown in Fig 4: an unaffected area (a), a region near the periphery of the corrosion pit (b), and a region near the center of the corrosion pit (c). From these photographs, it is obvious that the corrosion is localized but not as a cracklike defect but as a corrosion pit. The corrosive path is along the weld fusion boundary (the interface between melted and unmelted regions) with preferential corrosion of the resolidified weld metal. Note that the interior diameter of the corroded volume greatly exceeds the size of the leak site at the weld surface. This indicates that the corrosive process slows once the corrosive penetration through the thickness of the weld is complete. Completion of the corrosive penetration results in external leakage and necessarily dilutes the local environment within the corrosion pit. This result implies the existence of an aggressive media within the corrosion pit during its development, and assuming a relatively stable water chemistry, one that develops within the pit. It is well known that chlorides can produce acidification of the corrosion pit and greatly increase the rates of corrosive penetration.

The key to avoiding this type of damage is to prevent the initiation of corrosion pits. A number of characteristics in these tanks can contribute to pit initiation, among them: corrosion products due to oxidation of the weld backsides, incomplete weld penetration which forms crevices, and high chloride contents. Stainless steels which contain additions of Mo, such as type $316 \mathrm{~L}$, provide improved resistance to pit initiation. Accelerated corrosion is likely to be assisted by crevices and precipitate that shields the corrosion pit from oxygen and from recirculation of its aqueous environment with the bulk tank fluid.

\section{Rework of TFD-Type Tanks}

Two repair procedures were required for the TFD-type tanks. One was to repair the leaking tanks installed at TFD, and the second was to rework the unused tanks to prevent similar occurrences. The repair of the leaking tanks was considered as an immediate need and due to difficulties in welding from inside the tanks, filler material was added to the outside of the existing GTA welds. A GMAW process with type 308L filler wire was used which deposited significantly more weld metal than was present from the GTA welds. Both TFD tanks and the TFC tank were given this repair. The repair was successful in prolonging the life of these tanks but at the time of this writing, TFD tanks are again leaking at several weld sites in a manner similar to that experienced with the initial fabrication. 
The approach taken to rework the unused tanks was to develop qualified welding procedures and demonstrate acceptable corrosion periormance in test welds prior to implementing the repair procedures. Due to the limited accessibility in which to institute GTA welds from inside of the fabricated tanks, a GMAW process was selected. The GMAW process is characterized by motorized wire feed through a welding gun that can be hand held, eliminating the need for separate heat and wire manipulation (as in GTA welds). Unlike GTA welding, an arc is established between the consumable wire and the workpiece resulting in molten metal transfer across the arc gap. The shielding gas, consisting of $2.5 \% \mathrm{CO}_{2}$ for arc stability in an inert gas mix of $90 \% \mathrm{He}-7.5 \%$ Ar protects the weld surface from the surrounding air. While GMAW is not as controlled or as clean a process as GTAW, the ease of use and high rate of metal deposition make it the most common method of joining stainless steel.

In the first set of three GMA test welds, the welding parameters were varied over a range of voltages between 24 and $28 \mathrm{v}$ with resulting wire feed rates of 35 to 51 inches per minute. Test welds, 6 inches $(250 \mathrm{~mm})$ in length welds were produced on the inside of $304 \mathrm{~L}$ corner joints prewelded from the outside by GTAW to duplicate original tank fabrication procedures. The filler metal was 0.030 inch $(0.76$ $\mathrm{mm}$ ) diameter $316 \mathrm{~L}$ welding wire. Metallographic sections of the welds were prepared and revealed sound welds with good fusion along the edges of the weld and no evidence of cracking, as shown in Figure 5. Excessive convexity was present in the welds prepared at the higher voltages, with the $24 \mathrm{v}$. weld having the best weld shape. Weld penetration was roughly constant and was just short of reaching the GTA welds made from the opposite side; this left a small unwelded section at the center of the plate, as shown in Fig. 5, but is of no consequence to the corrosion resistance of the weld surfaces. The weld deposits were typical of a mixed-mode of metal transfer (short circuit/globular) and weld spatter was present but not excessive. Oxidation on the top surface of the GMAW welds was relatively heavy, with black oxide extending into the HAZ and cracking of the oxide within the weld metal deposit. For corrosion testing purposes, one set of welds were tested as-welded and another duplicate set was wire-brushed to remove the suriace oxide. Despite brushing with a rotary wire wheel, the surface roughness prevented complete removal of the oxide, particularly at spatter drop locations. Corrosion tests were initiated in tap water within a stainless steel bucket. Results revealed heavy buildup of corrosion products on the brushed regions after only 5 days exposure, later determined to be due to inadvertent use of a carbon steel brush versus the proper stainless steel brush. As-welded regions showed minimal rusting with minor discolorations at spatter droplets and widely scattered locations within the weld metal.

Additional GMAW test welds were fabricated ( $24 \mathrm{v}$. and $35 \mathrm{inch} / \mathrm{min}$ wire feed) using $316 \mathrm{~L}$ filler in one set and $308 \mathrm{~L}$ filler metal in another for comparison. The welds were each cut in half; one set was left as-brushed with a stainless steel rotary wheel and the second set was brushed and chemically passivated in nitric acid (approximately $30 \%$ ) for $4 \mathrm{~h}$ at RT. This passivation treatment is standard practice for removing surface contaminants and producing a thin protective suriace oxide and was performed by the MMED Plating Shop at LLNL. After 4 days exposure in TFD the samples were inspected for corrosion. The $308 \mathrm{~L}$ and $316 \mathrm{~L}$ welds behaved similarly with rust discolorations at spatter droplets (308L iiller) and 
up to 2 isolated locations in the weld metal of as-brushed welds. Only much lighter interference colorations were present in samples chemically passivated, again ai spatter droplets with the $308 \mathrm{~L}$ filler and at several weld metal locations with the $316 \mathrm{~L} \mathrm{filler}$. The corrosion was superficial in extent for both filler metals and the corrosion resistance was noticeably improved by wire brushing and further improved by the chemical passivation treatment.

The weld procedures developed through the test welds were incorporated into a welding specification reproduced in Appendix A. An unused TFD-type tank was weld repaired using this procedure although some deviation was required to weld a particularly difficult location to access. A SMA ("stick") weld using a matching $308 \mathrm{~L}$ covered electrode was used in this location. After completion of all welding, the entire tank was given a passivation treatment at the MMED Plating Shop by pumping fluid into the tank and tilting the tank to several positions. The first reworked tank was targeted for installation at LLNL Site 300.

\section{Weld Procedures for New Construction}

For optimum corrosion resistance a GTAW fabrication from inside the tank or with full penetration from outside the tank is recommended. Welding from inside the tank is preferred due to minimization of surface roughness and oxidation of areas exposed to the service environment on the interior of the tank. Inert gas shielding, (e.g. Argon) on the tank interior is recommended to minimize surface oxidation due to welding. To improve the resistance to pit initiation in chloride-containing environments, a Mo-containing stainless steel such as $316 \mathrm{~L}$ is recommended.

To test appropriate procedures, a series of specimens were produced using $304 \mathrm{~L}$ with $308 \mathrm{~L}$ filler metal, and $316 \mathrm{~L}$ with $316 \mathrm{~L}$ filler metal. The samples were GTA welded from both sides, brushed clean and half were chemically passivated in nitric acid. These samples were placed in TFC and TFD tanks for evaluation of corrosion resistance. Both tanks contained additions of a commercial phosphate inhibitor, JP7, to reduce the amount of calcium carbonate precipitate. In these conditions, no indications of corrosive damage were observed on the GTA welds after 4 months of exposure.

\section{Alternate Methods of Corrosion Protection.}

The difficulty of assuring adequate corrosion protection in stainless steel water tanks welded with poor practice may require the use of alternative methods. Two alternate approaches are: 1) the use of coatings, and 2) cathodic protection. Both methods have been suitably applied to protect systems in seawater environments, which is expected to be a representative yet more severe corrosion environment than in the TFC and TFD air stripper tanks. Coating systems have been widely developed for marine environments and are commercially available. Most of these systems are multicoat processes designed to provide layered protection for a finite lifetime. These coatings would need to be evaluated on a case by case basis to determine whether they introduce unacceptable contaminants into the purified groundwater. A second alternative is cathodic protection. This method is widely and successfully employed to protect marine systems as well as buried steel pipelines. While voltages from sacrificial anode materials such as zinc offer 
protection to general corrosion, voltages of approximately 1.0 volt are recommended for protection of stainless steels against pitting [3]. To experimentally evaluate the benefits of cathodic protection, a DC power supply was connected to a welded test sample within a TFD tank and 1.0 volts impressed onto the sample relative to an auxiliary electrode. While no corrosion of the welded sample was observed, control samples also remained uncorroded. Of note, the cathodically protected sample rapidly developed a dense calcium carbonate coating. Such cathodic reactions can reduce the current requirements to protect a sample by helping to distribute the protective current [4]. Cathodic protection is especially attractive because it can be applied to a system whether or not corrosion has previously been initiated. The difficulty in applying this method to an enclosed system, however, is the production of hydrogen at the auxiliary electrode. Hydrogen safety requires maintaining these levels below flammable limits and hydrogen monitors and additional safety planning may be required.

\section{CONCLUSIONS}

The rapidly developed leaks within the TFC and TFD tanks were caused by localized corrosion within the resolidified weld metal. The corrosion was initiated by the severe oxidation of the backsides of the welds which left the exposed surfaces in a condition highly susceptible to aqueous corrosion.

The propagation of surface corrosion through the thickness of the welds occurred by localized corrosive attack. This localized attack was promoted by the presence of shielded aqueous environments provided by crevices at the root of the partial penetration welds. In addition to rapid corrosion of oxidized surfaces, calcium carbonate precipitation provided an additional source of physical shielding from the bulk tank environment.

Qualification testing of alternate weld procedures showed that corrosion damage can be prevented in 304L stainless steel GTA welds by welding from both sides while preventing oxidation of the tank interior through the use of an inert backing gas such as argon. Corrosion resistance was also satisfactory in GMA welds in which oxidized surfaces were postweld cleaned by wire brushing and chemically passivated in nitric acid. Further improvements in corrosion resistance are expected from a Mo-containing grade of stainless steel such as type $316 \mathrm{~L}$, although test results were similar for type 304L sheet welded with type $308 \mathrm{~L}$ filler metal and type $316 \mathrm{~L}$ sheet welded with type $316 \mathrm{~L}$ filler metal. 


\section{REFERENCES}

1. S. Turner and F. P. A. Robinson, "The Effect of the Suriace Oxides Produced during Welding on the Corrosion Resistance of Stainless Steels", Corrosion, 1989, pp. 710-718.

2. W. J. Sperko, "Purge to Protect Stainless Steel Pipe Welds", Welding Design \& Fabrication, 1995, pp. 26-27.

3. D. Peckner and I. M. Bernstein, in "Handbook of Stainless Steels", McGraw-Hill Book Co., 1977, p. 37-4.

4. H. Uhlig, in "Corrosion and Corrosion Control", John Wiley \& Sons, Inc., 1963, p. 174. 


\section{LIST OF FIGURES}

Figure 1. View of the interior of the TFD air stripper tank characterized by incomplete weld penetration and rust colored corrosion deposits at the lower weld seams.

Figure 2. Duplicate weld cross-sections of corner welds in $0.115^{\prime \prime}$ thick $304 \mathrm{~L}$ : (a) autogenous GTA weld; (b) GTA weld with $308 \mathrm{~L}$ filler metal; (c) autogenous GTA root pass with $308 \mathrm{~L}$ filler on a second GTA weld pass.

Figure 3. Optical metallography of leaking weld site removed from the TFC tank:

(a) the underside of the weld on the tank interior contains heavy corrosion deposits;

(b) the outer surface of the weld contains a small diameter hole.

Figure 4. Optical cross-sections of a leaking weld site removed from the TFC tank (32X): (a) an unaffected area; (b) a region near the periphery of the corrosion pit; (c) a region near the center of the corrosion pit.

Figure 5. Optical cross-sections of GMAW repair welds (12.8X): (a) 24 volts; (b) 26 volts; (c) 28 volts. 

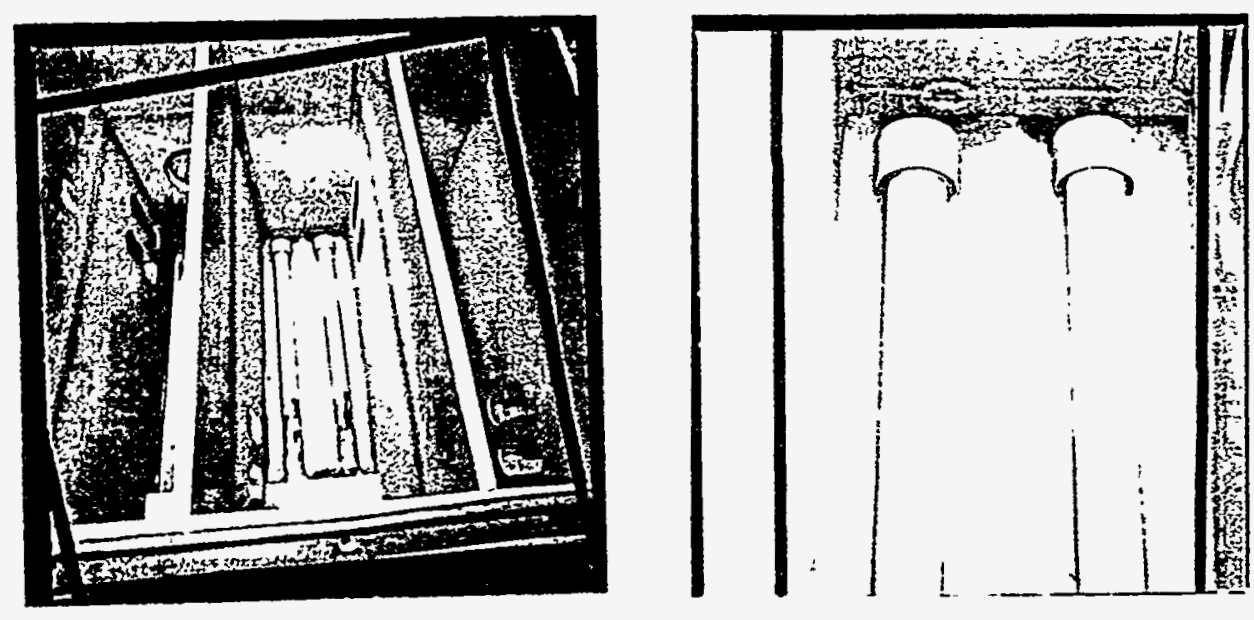

Figure 1. View of the interior of the TFD air stripper tank characterized by incomplete weld penetration and rust colored corrosion deposits at the lower weld seams.

(a)

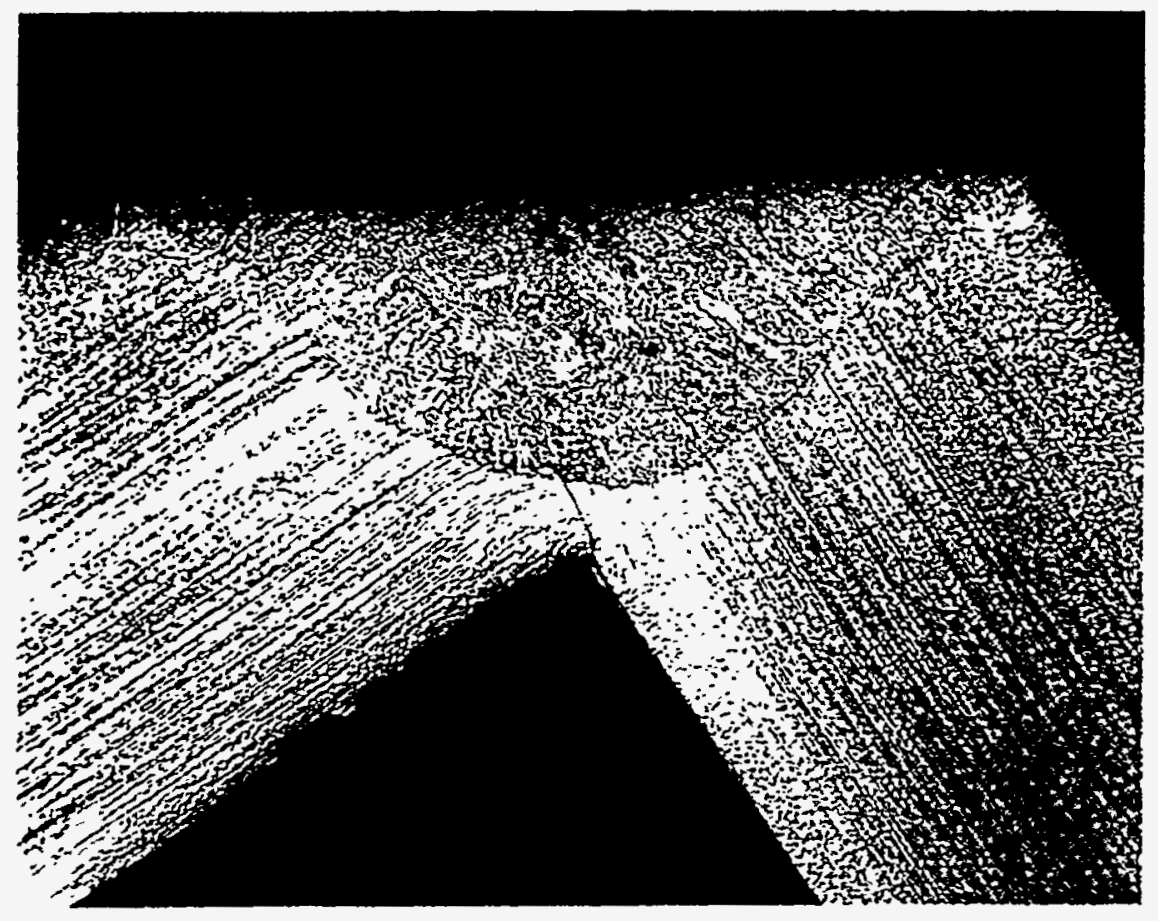

$0.5 \mathrm{~mm}$

Figure 2. Duplicate weld cross-sections of corner welds in $0.115^{\prime \prime}$ thick $304 \mathrm{~L}$; (a) autogenous GTA weld. 
(b)

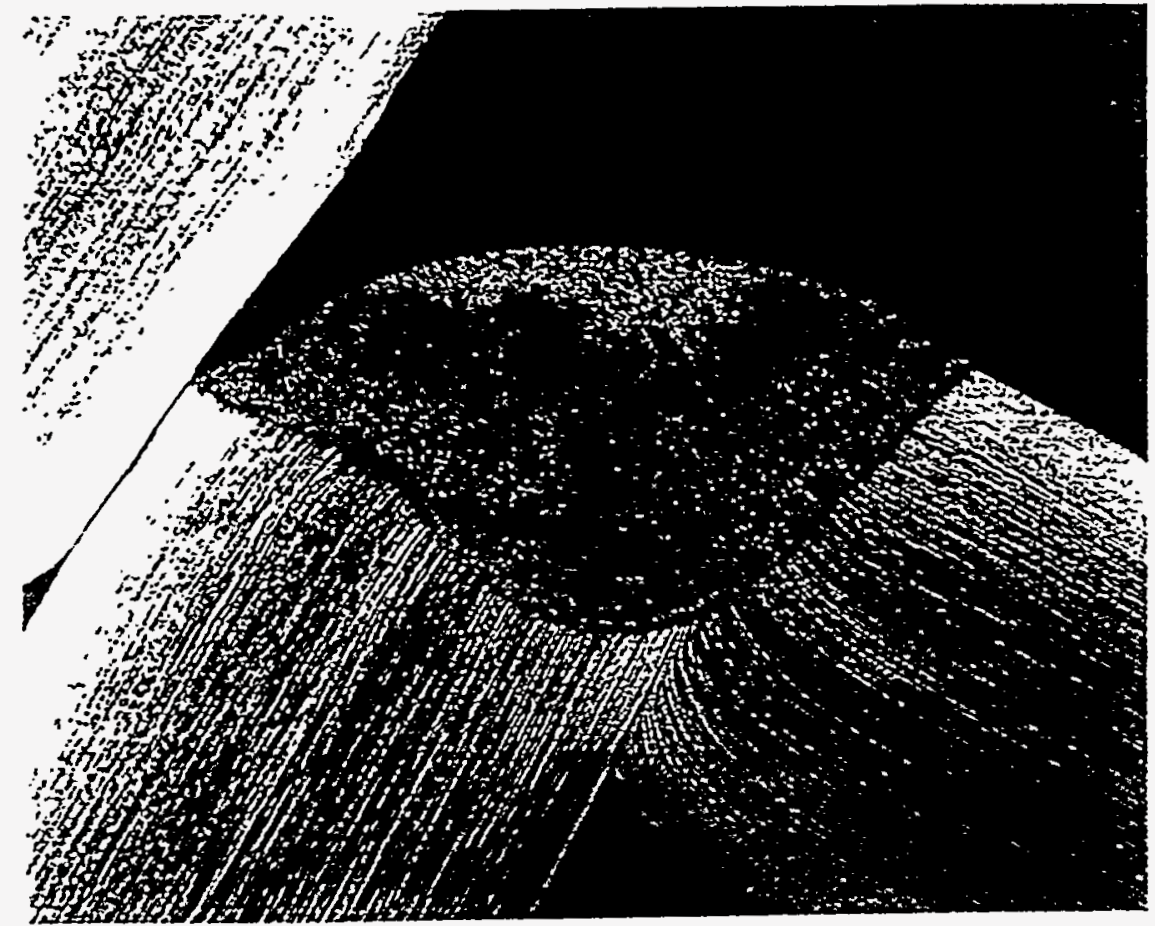

\section{$0.5 \mathrm{~mm}$}

(c)

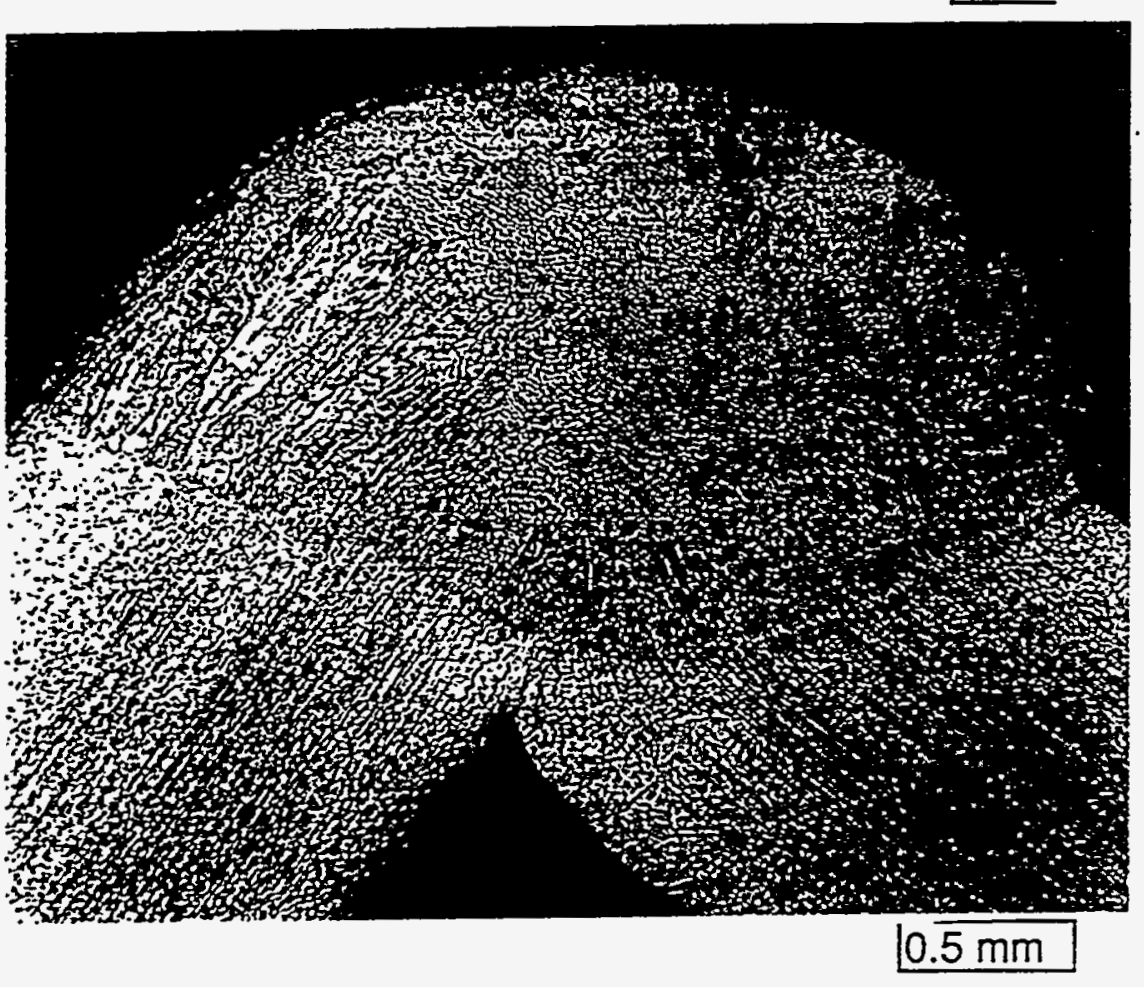

Figure 2 (cont'd). Duplicate weld cross-sections of corner welds in $0.115^{\prime \prime}$ 'thick 304L; (b) GTA weld with 308L filler metal; (c) autogenous GTA root pass with 3CE:iiller on a second GTA weld pass. 
(a)

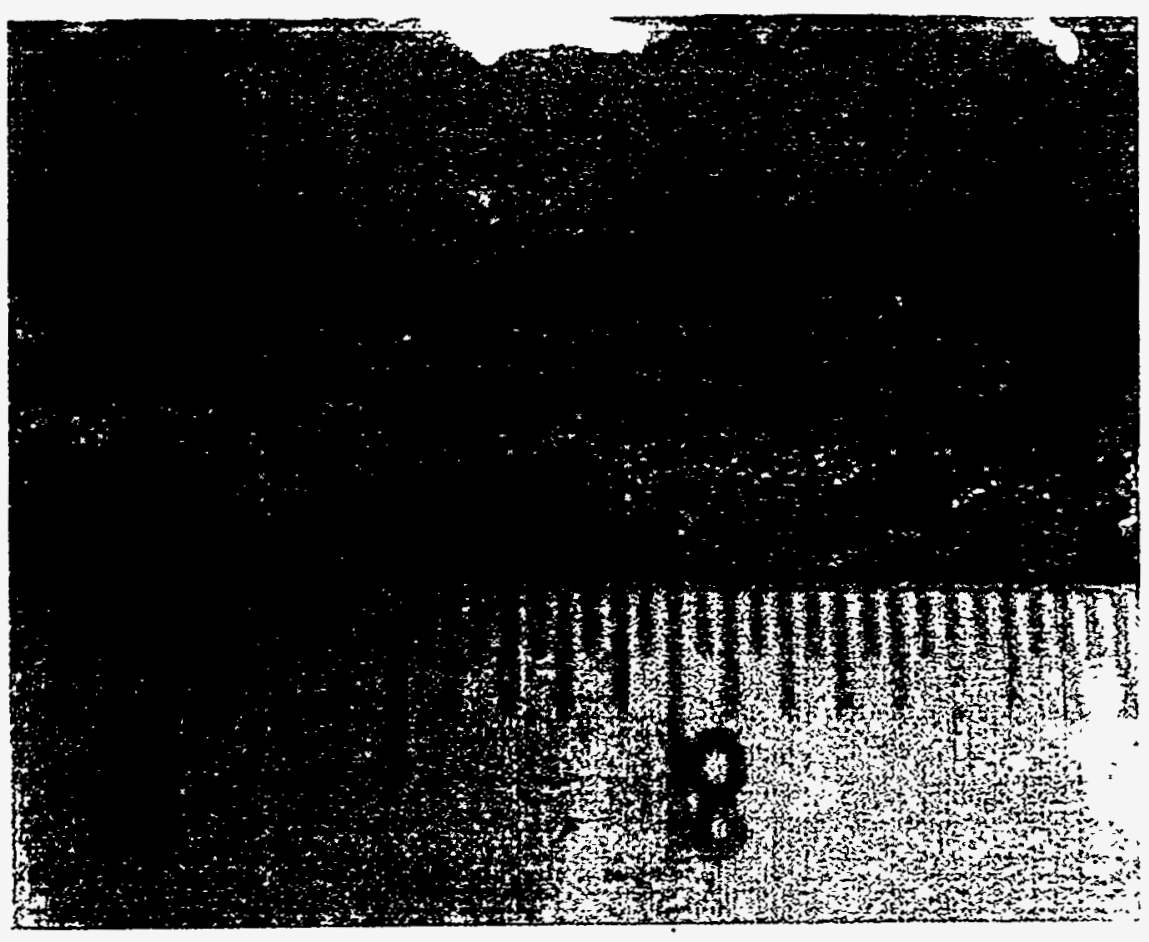

(b)
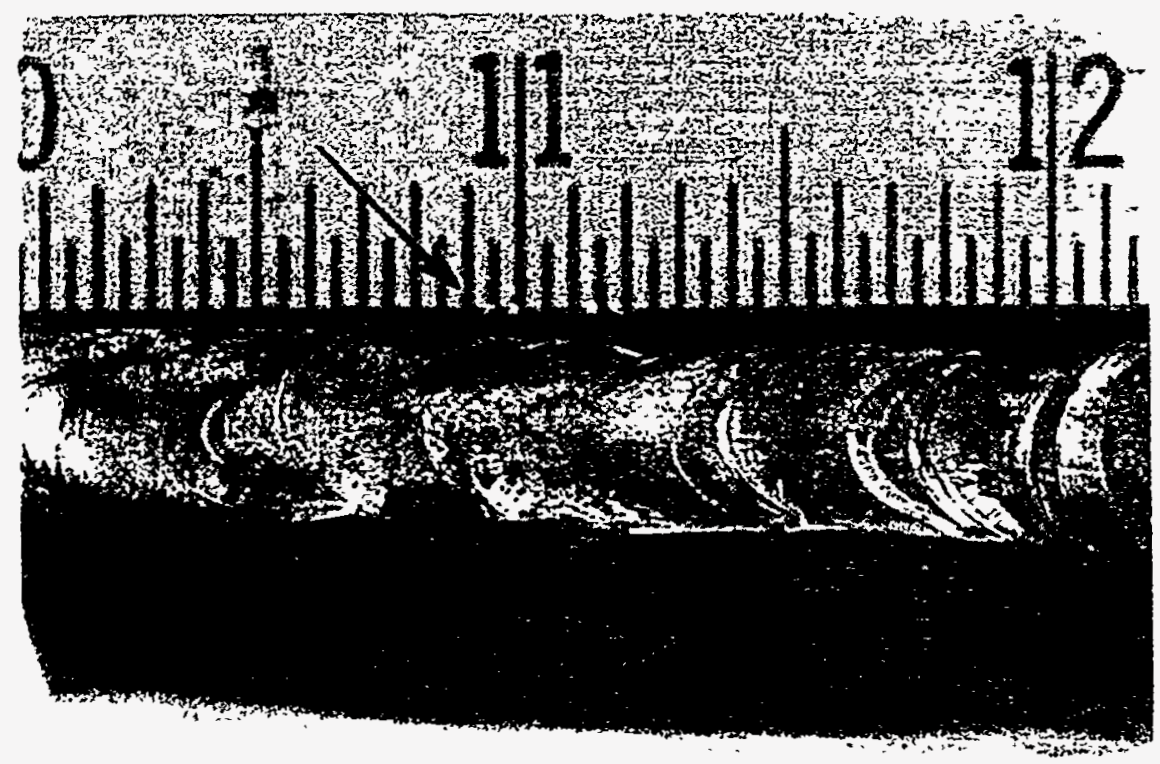

Figure 3. Optical metallography of leaking weld site removed from the TFC tank:

(a) the underside of the weld on the tank interior contains heavy corrosion deposits:

(b) the outer surface of the weld contains a small diameter hole. 
(a)

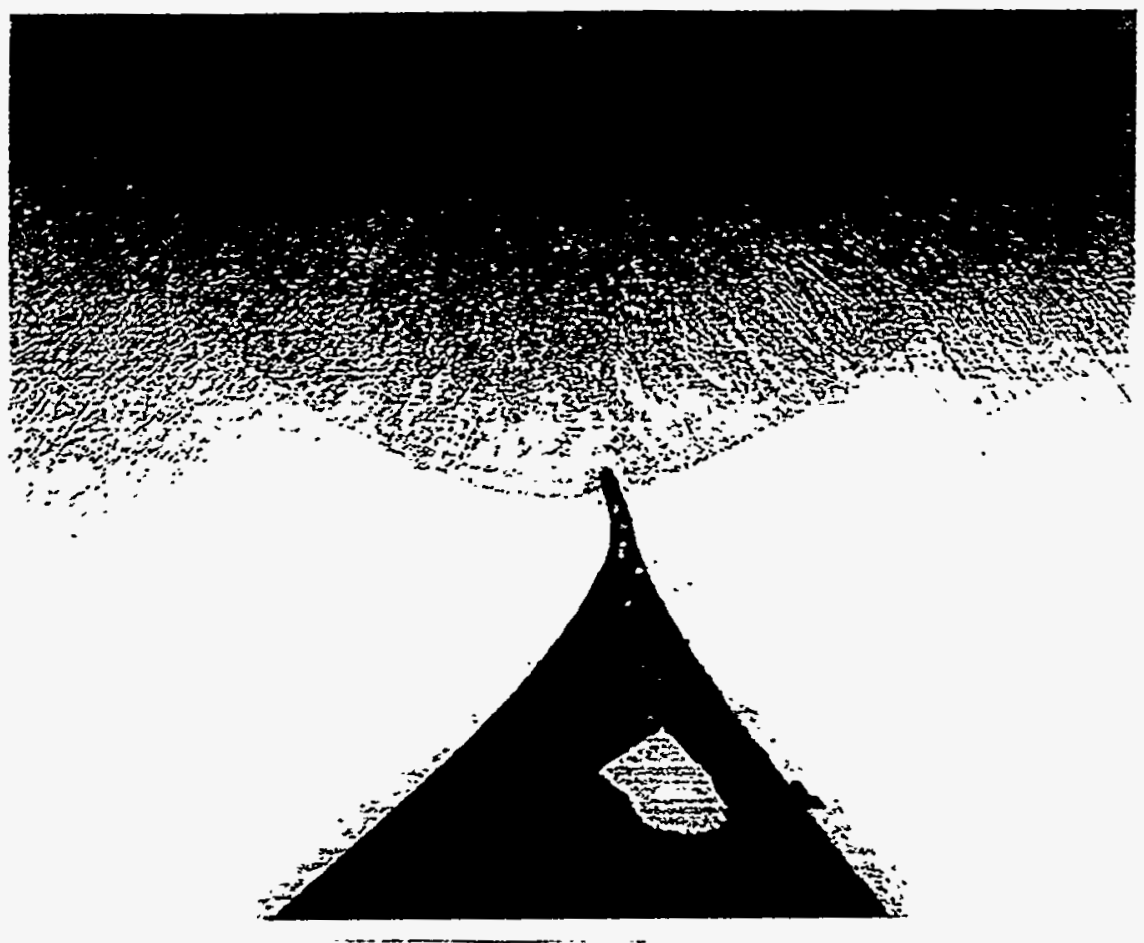

(b)

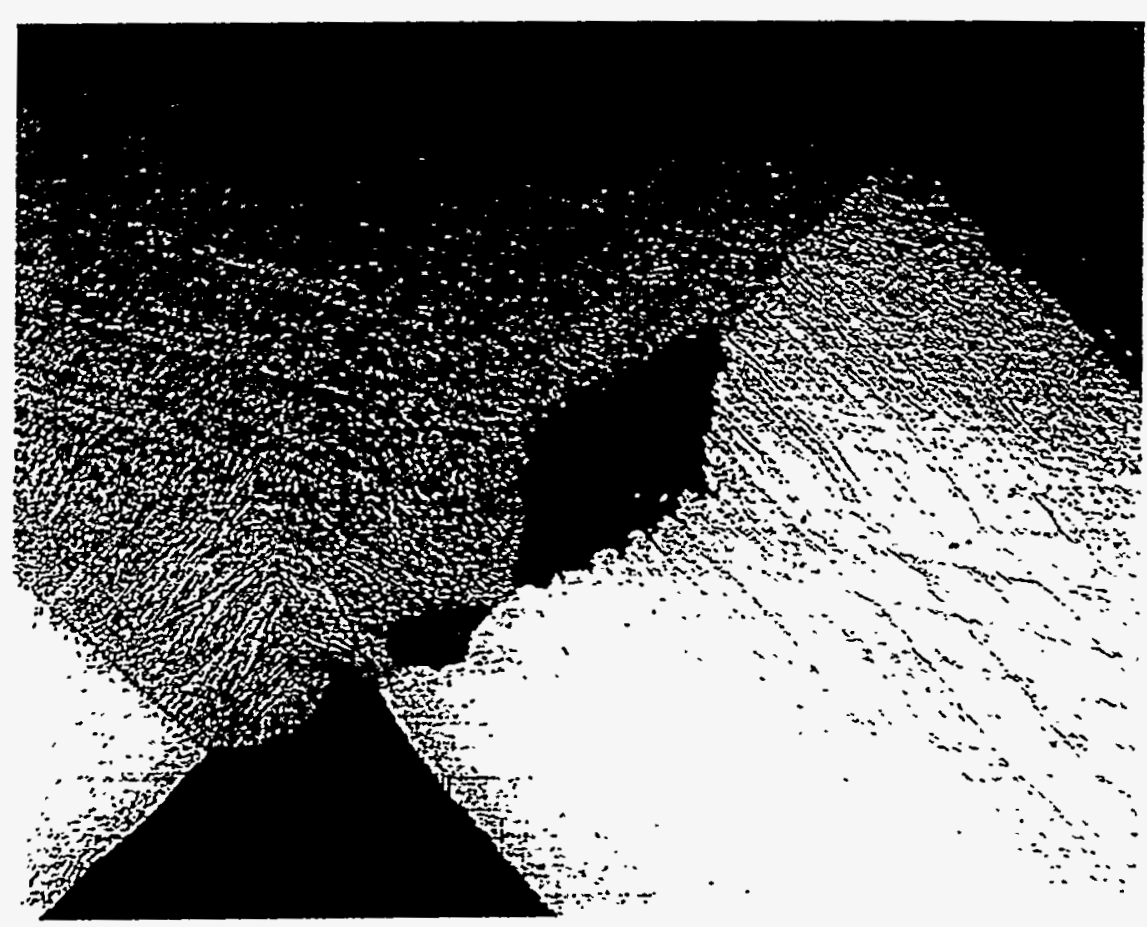

Figure 4. Optical cross-sections of a leaking weld site removed from the TFC tank $(32 X)$ : (a) an unaffected area, (b) a region near the periphery of the corrosion pit. 
(c)

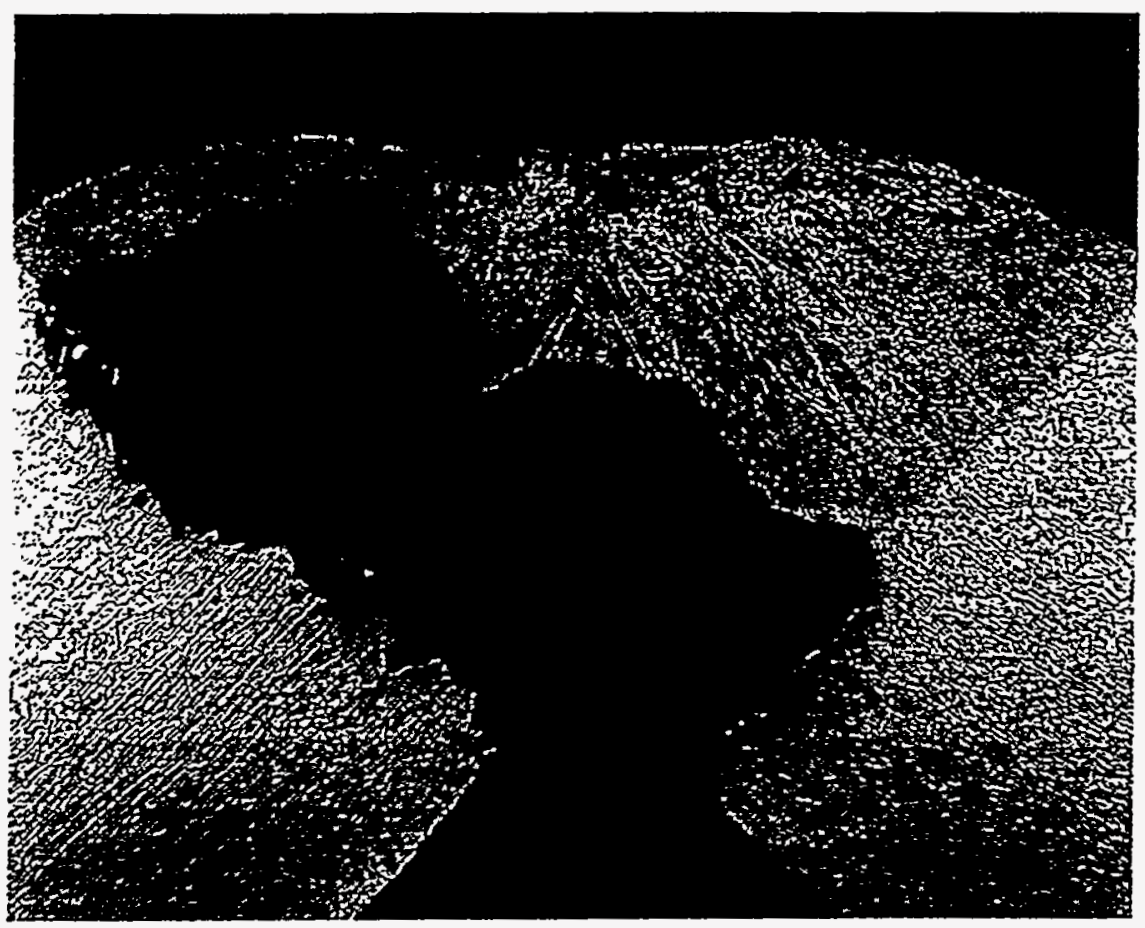

Figure 4 (cont'd). Optical cross-sections of a leaking weld site removed from the TFC tank (32X): (c) a region near the center of the corrosion pit.

(a)

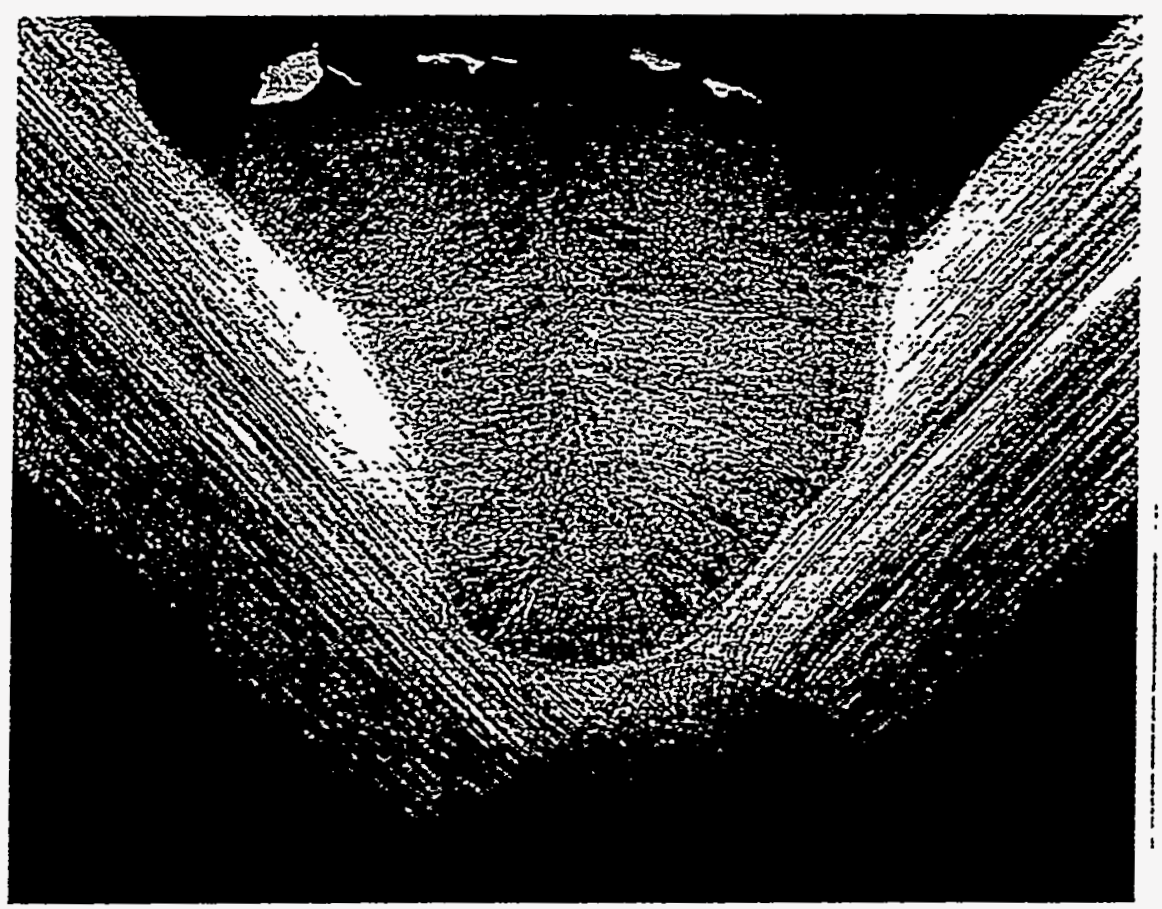

Figure 5. Optical cross-sections of GMAW repair welds (12.8X): (a) 24 volts. 
(b)

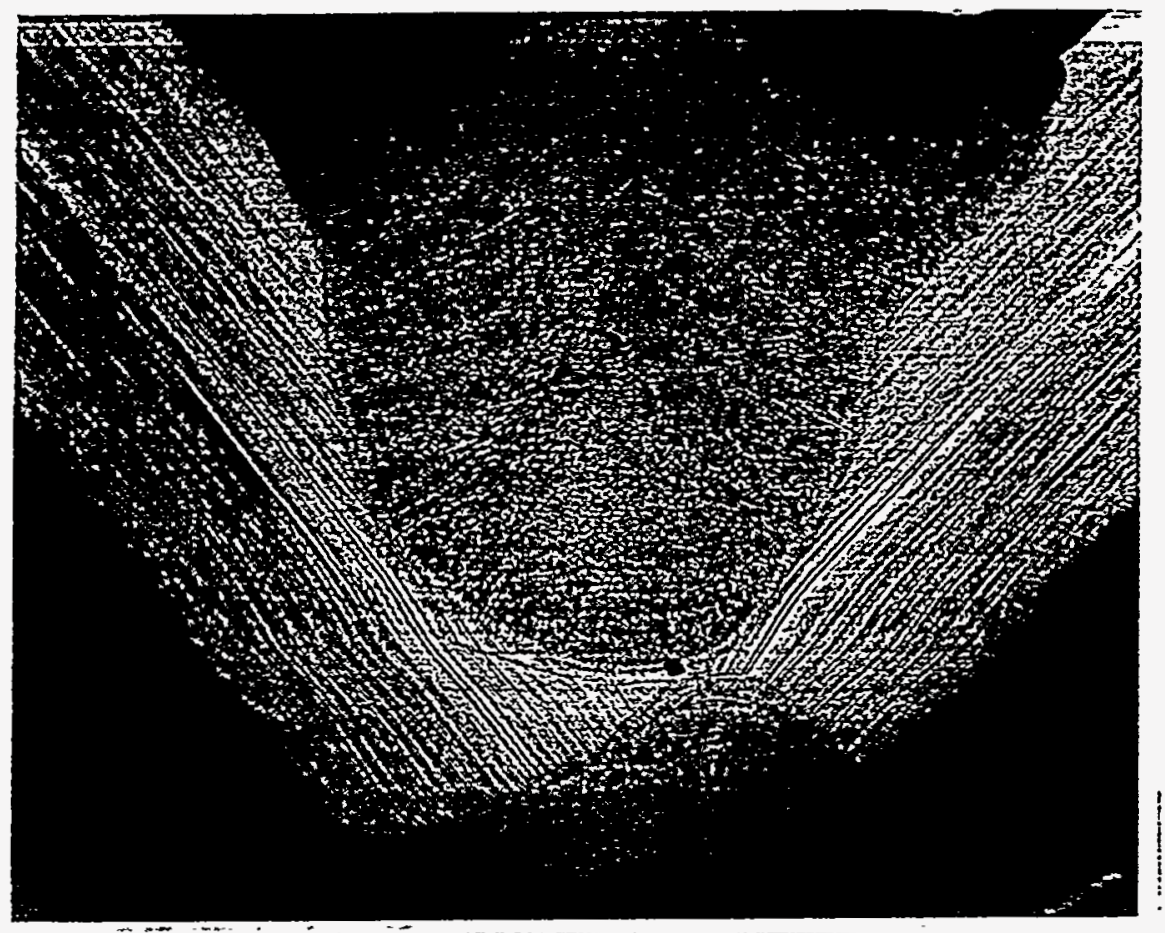

(c)

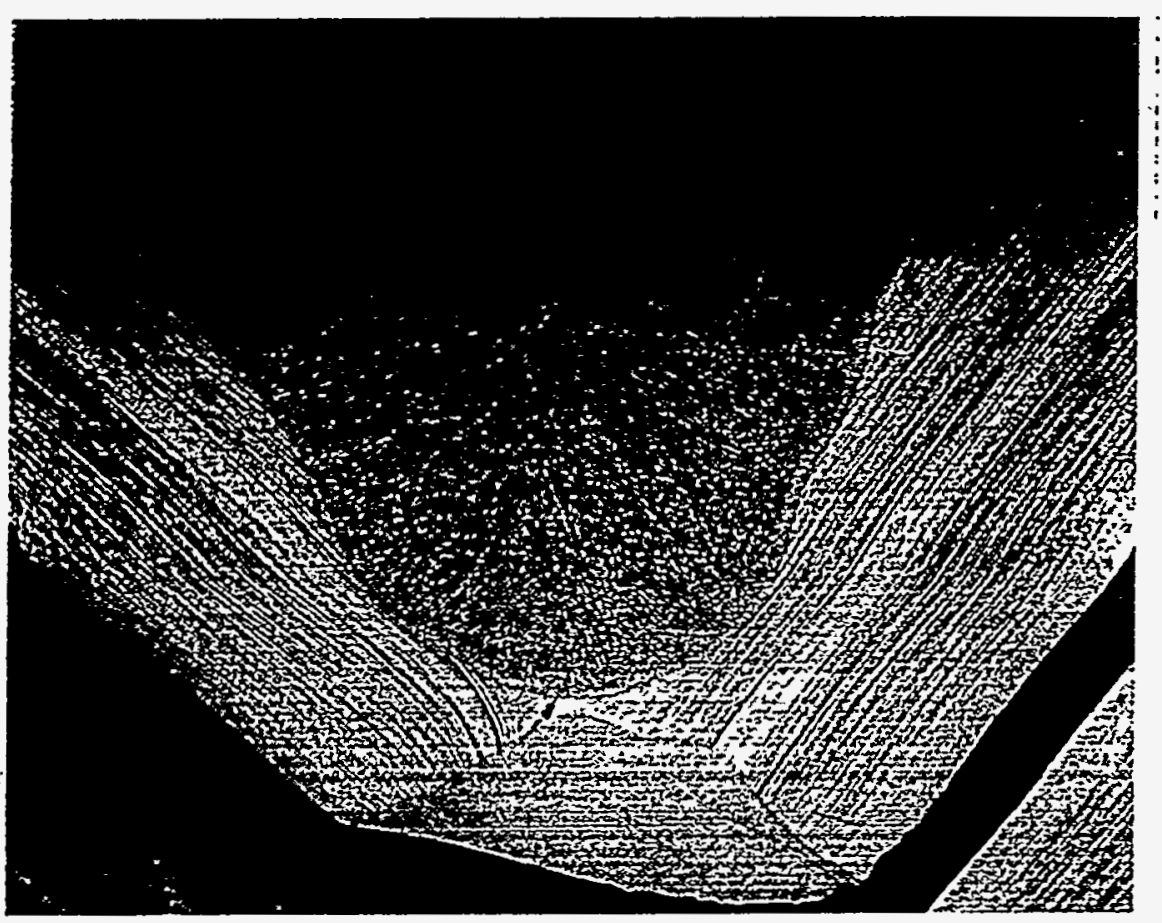

Figure 5. Optical cross-sections of GMAW repair welds (12.8X): (b) 26 volts, (c) 28 volts. 